\title{
A pena e o bacamarte: imprensa e narrativa criminal - um olhar sobre a cidade no século XIX
}

The quill-pen and the blunderbuss: press and criminal narrative - an approach to the city in the nineteenth century

\author{
Sônia Maria de Meneses Silva*
}

\begin{abstract}
Resumo
Este artigo pretende analisar as narrativas jornalísticas sobre a violência na cidade de Fortaleza na segunda metade do século XIX. O objetivo é compreender como os discursos divulgados nos periódicos pretendiam auxiliar na divulgação de uma lógica civilizatória para o controle da população. Tal aspecto pode ser percebido por meio de um contínuo processo que visava à centralização da força na capital cearense para a qual a imprensa atuou como um de seus principais agentes.
\end{abstract}

Palavras-chave: Cidade; Violência; Imprensa.

\begin{abstract}
This article aims to analyze the journalistic narratives on violence in the city of Fortaleza in the second half of the nineteenth century. The objective is to understand how the discourses published in periodicals intended to control the population and the centralization of power in Fortaleza. The emphasis is especially on events such as assassinations and police violence in the city space.
\end{abstract}

Keywords: City; Violence; Press.

\section{A Cidade das "tendências perigosas"}

Não vos estranhais as causas e os incentivos dos crimes. Os obstáculos que existem e que impedem, fora de toda a dúvida, a prática das garantias constitucionais, são dignos de reparo. O povo das classes menos instruídas, sem a necessária educação civil e religiosa, desconhecedor de seus direitos e deveres e contando com a impunidade, vai manifestando tendências perigosas, cometendo crimes de muita gravidade. (CONSTITUIÇÃO, 21/07/1871, p. 1).

A narrativa acima, extraída do jornal cearense A Constituição, de 1871, nos apresenta vários elementos presentes nos debates sobre a ordenação dos espaços urbanos no século XIX e, mais especificamente, sobre as práticas e discursos acerca da

\footnotetext{
* Doutora em História pela Universidade Federal Fluminense (UFF). Professora do Mestrado Profissional em História da Universidade Regional do Cariri (URCA). Professora do Programa de Pós-graduação em História da Universidade Estadual do Ceará (UECE).
} 
violência e a necessidade de seu controle. De partida, chama atenção para o fato de que a garantia dos direitos individuais e de propriedade não eram assegurados naquela sociedade e embora constate que existissem recursos legais que garantiriam tais direitos, no cotidiano, aquelas conquistas ainda estavam bastante distantes dos ideais preconizados pelos redatores do jornal. A matéria vai além de uma constatação, ela aponta explicações e, consequentemente, culpados para a recorrência de tantos crimes, segundo ela, atribuídos ao "povo das classes menos instruídas que, sem instrução moral e religiosa estava livre para cometer toda sorte de crime".

Entre os anos de 1848 a 1860, foram cometidos 2.952 crimes na província cearense. Desse total, 734 foram homicídios e 1510 foram ferimentos e ofensas físicas; esses números indicam uma média anual de 114 assassinatos e de 294 de ofensas físicas e ferimentos (SOUSA BRASIL, 1860, p. 787). Tais números causaram espanto a Thomaz Pompeo de Sousa Brasil ${ }^{1}$ em seu Ensaio Estatístico sobre a província cearensepois, segundo ele, "o termo médio dos atentados contra a vida é tão acrescido que só os estados menos policiados da Europa dão uma proporção aproximada" (SOUSA BRASIL, 1860, p. 787). Enquanto no Ceará a proporção era de 1 crime contra a vida por 2.241 habitantes, Pompeu menciona que na França essa proporção era de 1 por 390.000 habitantes, Escócia 1 por 270.000 e na Grã-Bretanha, 1 por 178.000. Thomaz Pompeo de Sousa Brasil atribui esse fato à "moralidade do nosso povo", ainda bastante distante do ideal de civilização preconizado.

Diante desse quadro, a contenção do crime era um ponto fundamental para a elite cearense, especialmente, quando se colocava em cena as pretensões de uma sociedade que queria se ver civilizada, mais ainda, queria que os meios legais na mediação dos conflitos obtivessem sucesso no ordenamento urbano da capital cearense. Todavia, em toda a província, eram comuns os "atentados contra a vida" e homicídios como resultado de disputas político-partidárias, ou como manifestações de conflitos pessoais.

A crítica a essas ocorrências é feita tendo como base a necessidade de um controle sobre a população, a instalação de mecanismos de punição racionalizados e a construção de instituições corretivas, dentre outras ações. Moralizar a população seria o primeiro passo para civilizá-la pois, segundo o jornal O Cearense, enquanto isso não

\footnotetext{
${ }^{1}$ Além do conhecido interesse de Thomaz Pompeo de Sousa Brasil pela história da província cearense, notabilizando-se por suas pesquisas, atuou fortemente na política cearense, sendo senador pelo partido liberal e fundador do jornal O CEARENSE.
} 
acontecesse, "não [haveria] pessoa por mais elevada, não [haveria] lugar por mais público que [estivesse] a abrigo do bacamarte ou do punhal do facínora" (O CEARENSE, 26/07/1850, p. 2).

O crescimento desordenado de Fortaleza, na segunda metade do século XIX, era um dos graves problemas enfrentados na cidade. Os principais fatores que $o$ proporcionavam eram as calamidades nas outras regiões da província, que empurravam centenas de retirantes para a capital, além do desenvolvimento econômico da cidade que atraía pessoas de províncias vizinhas. Essa situação estimulava graves crises sociais, pois a insatisfação gerada pelas pestes cíclicas ${ }^{2}$ e pelos períodos de seca demostrava a fragilidade estrutural da cidade.

Em 1845, a população de Fortaleza foi prevista pelo pesquisador e jornalista João Brígido em um total de 4200 habitantes (OUTRO ARAMAQUE - pseudônimo de João Brígido - 1958, p. 230-256). Já no início da década de 1860, Tomás Pompeo de Sousa Brasil estimava essa população em torno de 16.000 habitantes (SOUSA BRASIL, 1860). Mesmo guardando as devidas deficiências desses dados, é possível constatarmos que, a partir da segunda metade do século XIX, houve um crescimento significativo da população na capital cearense. Segundo Lemenhe, esse crescimento e "a posição de vila-capital da Capitania independente conferia à Fortaleza vantagens sobre as outras vilas na captação de recursos excedentes do campo para a edificação de obras" (LEMENHE, 1991, p. 63).

Apesar dos dados sobre a população de Fortaleza serem divergentes, uma vez que não se encontra um consenso numérico entre as várias estatísticas populacionais, o censo feito no Brasil em 1872 possibilita-nos uma boa visão de como estava organizada a população fortalezense na segunda metade do século XIX ${ }^{3}$.

Segundo aquele censo, Fortaleza contava com uma população de 21.372 habitantes, sendo que 20.191 eram homens livres e 1.183 eram escravos. Desse total,

\footnotetext{
${ }^{2} \mathrm{Na}$ segunda metade do século XIX, eram diversos fatores que contribuíram para o crescimento da população de Fortaleza, como a epidemia de febre amarela na década de 50, a grande seca de 1877/79, que foi acompanhada da epidemia de varíola. Além desses elementos, o crescimento da economia agrícola proporciona um intenso fluxo de comerciantes e habitantes das províncias vizinhas para a Capital.

${ }^{3}$ É difícil apresentar dados exatos da população da capital cearense, mas essa não era uma realidade exclusiva do Ceará, pois em todo o Brasil são inúmeras as deficiências desses dados. O próprio Thomaz Pompeo, que realizou um dos trabalhos estatísticos mais completos sobre a província cearense, reclama constantemente das dificuldades e dos problemas para se conseguir dados confiáveis: "Sabendo-se com que desleixo esses trabalhos são executados pelos agentes policiais, e quando o nosso povo, já por falta de ilustração, já por má vontade, e infundados receios de recrutamento imposto, se não presta a dar com exatidão as necessárias informações.” (SOUSA, 1997, p. 295).
} 
apenas 4.447 - 4.436 livres e 11 escravos - sabiam ler. O número de analfabetos era de 16.925 - 15.753 livres e 1.172 escravos. Aqueles sem profissão chegavam a quase 8 mil pessoas - 3495 homens e 4440 mulheres (IBGE, 1872).

Não se pode falar da organização social de Fortaleza no século XIX sem se mencionar os graves momentos de crise pelos quais passou a cidade em virtude das secas e de epidemias como a de febre amarela e principalmente a de varíola. Em 1877 e 1878 a cidade foi tomada por um enorme contingente de retirantes, o que aumentou em dez vezes sua população (TEÓFILO, 1997). Excetuando-se as pessoas que morreram em virtudes da varíola, que não foram poucas - somente em dezembro de 1878 registrou-se "a assombrosa cifra de 15.352 falecimentos" (TEÓFILO, 1997, p. 36) - a maior parte dos sobreviventes voltava para suas residências no interior da província. Entretanto, um bom número de retirantes permanecia na capital onde se tornavam mendigos já que muitos haviam perdido todos os seus parentes. Rodolfo Teófilo afirmava que, no final do trágico período de seca e varíola na capital,

[...] o número de cegos pela varíola era incontável. Dos lazarentos, haviam saído a mendigar pelas portas cegos de todas as idades, centenas de infelizes aos quais as pústulas variólicas haviam inutilizado. Eram também sem conta os chaguentos [...] entre a turba de esmolares causava grande pena as crianças, os pequeninos, órfãos de pai e mãe, que em companhia de mulheres vadias, de quem eram o ganha-pão, esmolavam cantando. (TEÓFILO, 1997, p. 38).

A partir dessa citação, é possível percebermos como Fortaleza tinha uma atmosfera de instabilidade social muito presente em seu cotidiano. Por ser a capital, havia sempre uma população flutuante que a procurava como refúgio, fosse das secas, fosse das pestes. Além disso, outros grupos sem ocupação fixa estavam presentes em seu espaço, como, por exemplo, os ex-escravos. Em 1853, o jornal O Cearense chamava a atenção do chefe de polícia e alertava: "existe nessa cidade e seus subúrbios um foco de imoralidade de todo o gênero, queremos falar da colônia africana de Samagolés".

Ainda segundo o jornal, os africanos teriam chegado à capital em 1835, sendo distribuídos a diversos proprietários porém, "ou porque completaram seu tempo, ou porque [os proprietários] se desgostaram deles, foram largados e aqui se acham quase todos no centro da cidade em casebres" (O CEARENSE, 19/08/1953). Tomando como referência esses dois grupos de habitantes que ajudavam a compor a população pobre de Fortaleza, podemos imaginar a tensão estabelecida nesse espaço, principalmente, 
quando levamos em consideração que os grupos de intelectuais, políticos e pessoas mais ricas da cidade estavam praticamente encastelados em cerca de "uns oitenta sobrados" espalhados no centro da cidade.

O progresso e a liberdade, proclamados como a panaceia da civilização, chegavam pelas mãos e pelas ideias de grupos de homens que seriam os responsáveis pela construção de um discurso civilizador na cidade de Fortaleza. Jornalistas, políticos, advogados e intelectuais representavam a emergência de setores urbanos que estavam preocupados em defender novos códigos que visavam à transformação do espaço da cidade.

Em meio à emergência desse discurso, Fortaleza era construída por territórios e espaços de experiência humana diversificados e conflitantes que compunham um rosto multifacetário. Para compensar essa grande disparidade, os grupos dominantes de Fortaleza vão progressivamente compondo um discurso que pretendia construir a cidade não somente materialmente mas, sobretudo, simbolicamente, pela da divulgação de outras condutas e comportamentos. Aliado a isso, há um projeto de transformação urbana da capital.

Em 1867, o jornal A Constituição (28/03/1867) afirmava que "quem tivesse vindo a essa cidade [Fortaleza] há uns cinquenta anos e vier agora não a conhecerá, suporá que está em outra terra”. Fortaleza sofreu uma mudança considerável em sua estrutura física entre a primeira e a segunda metade do século XIX, pois muitos dos "magníficos prédios" que imprimiam ares de civilidade e progresso à pequena cidade começaram a ser construídos a partir da década de 40 daquele século. Temos, por exemplo, o Hospital de Caridade, iniciado em 1847 e concluído durante a década de 50; o Cemitério Público, iniciado em 1848 e concluído em 1856; a Cadeia da Capital, iniciada em 1851; o Palácio da Assembleia, iniciado em 1856; a Casa de Educandos, iniciada em 1856 e concluída em 1860; o Quartel de Polícia, iniciado em 1847, e a Cavalariça da Polícia, iniciada em 1857 (SOUSA BRASIL, 1860, p. 707-711).

Nesse contexto do século XIX, os jornais do século passaram a exercer um papel ativo nas acirradas discussões políticas das províncias (SODRÉ, 1999). Em matérias, com um forte caráter opinativo, a palavra impressa tornava-se um recurso poderoso nas disputas e construção de novas simbologias para aquele cotidiano. Por outro lado, ganhava corpo no espaço das cidades a formação de uma opinião pública cada vez mais evocada pelos periódicos. "Se, por um lado, aparentemente a disputa partidária se apresenta como ponto central nas discussões desses jornais, [...] por outro lado, é 
inegável a insistência na construção de conceitos de caráter moralista nas publicações” (SILVA, 2000, p. 128).

Ao tentar compreender a estruturação de um discurso civilizador sobre as condutas criminosas na capital cearense, é fundamental percebermos o papel que assume a imprensa de Fortaleza no século XIX. Através dela, cotidianamente, os acontecimentos que antes eram tratados como eventos particulares e isolados ganham uma conotação pública que influenciará significativamente a transformação dos hábitos dos moradores da cidade. Somente em Fortaleza, dezenas de jornais circularam tratando sobre os mais variados assuntos e, embora exercessem uma impressa fortemente marcada pelas facções políticas, traziam à tona uma série de acontecimentos do dia a /dia da cidade.

As primeiras manifestações jornalísticas cearenses ocorrem na década de 1820 com a publicação da Gazeta do Ceará, um jornal oficial que servia para prestação de contas do governo. Contudo, é bem provável que, mesmo antes disso, folhetos ou pequenos informativos tenham sido editados e tido uma circulação razoável na província, pois há referências em jornais posteriores a coletâneas de leis e ofícios publicados nesses informativos. No entanto, é na segunda metade do século XIX que a imprensa cearense consegue se estabelecer efetivamente com a atuação dos jornais Pedro II, do partido conservador, e $\mathbf{O}$ Cearense, do partido liberal.

Segundo o historiador Geraldo Nobre (2006), no final da primeira metade do século XIX, funcionavam na província cearense no mínimo cinco tipografias, das quais saíam desde folhetos oficiais do governo até jornais artístico-literários de oposição. As primeiras tipografias foram montadas com a participação de tipógrafos de outras províncias que eram contratados para realizar essa atividade no Ceará. Alguns deles desenvolviam outras atividades, principalmente as de livreiro e de colecionador de documentos, o que nos demonstra que a organização jornalística proporcionou o estabelecimento de outras atividades de caráter intelectual. Inicialmente, $\mathbf{O}$ Cearense foi impresso pelas tipografias Imprensa Nacional e Tipografia Brasileira de Paiva \& Cia, sendo que a primeira era a mais antiga e tradicional da província.

Surgindo em 1846 na capital da província, O Cearense tornou-se um forte mecanismo político até a proclamação da república quando foi extinto. Outro jornal bastante influente nesse período era o jornal A Constituição que surgiu a partir de uma cisão do jornal Pedro II na década de 1860. Como eram diretamente ligados a partidos políticos, os jornais constantemente sofriam represálias e muitos editores e tipógrafos 
eram perseguidos, principalmente, quando o grupo opositor estava no poder. $\mathrm{O}$ trabalho de tipografia dos jornais era realizado por uma categoria bastante especializada que aprendia o ofício a partir de relações familiares ou de amizade. Uma das principais maneiras que o grupo político que estava no poder encontrava para dificultar a edição dos jornais da oposição era o recrutamento feito entre os tipógrafos, o que inviabilizava por algum tempo a publicação desses periódicos.

Tanto $\mathbf{O}$ Cearense quanto A Constituição tiveram uma atuação bastante dinâmica enquanto mecanismos de discussão e divulgação de conceitos como civilização e legalidade no espaço urbano. Apesar de pertencerem a grupos políticos distintos, há uma aproximação dos dois jornais quanto à ideia de se estabelecer novos padrões de comportamento na cidade. Como afirmava O Cearense, em editorial de 05/01/1850: “O importante era salvar a causa da civilização e da humanidade”. Somente dessa forma, segundo A Constituição (26/04/1970), seria estabelecido o "reinado da ordem".

Os redatores de ambos os jornais eram, em sua maioria, homens ligados a uma ativa vida política; muitos faziam parte da assembleia provincial e ao mesmo tempo eram intelectuais. Dentre os editores, nomes como Thomaz Pompeo de Sousa Brasil (Senador Pompeo), Tristão de Alencar Araripe e João Brígido marcaram os artigos publicados nos jornais, sobretudo, porque, além de ligados a um partido político, exerciam também diversas atividades nos campos social e intelectual da província.

Tristão de Alencar Araripe, por exemplo, tinha uma constante preocupação com a história do Ceará, recolhendo documentos e artigos por meio de anúncios no próprio O Cearense. O Senador Pompeo, editor do jornal O Cearense, foi o responsável por boa parte dos editoriais do jornal, em que manifestava severas críticas aos seus opositores, além de redigir artigos diversos sobre questões como moralidade, segurança, política, dentre outras. Thomaz Pompeo de Sousa Brasil notabilizou-se também por vastas pesquisas sobre a história da província, sendo de sua autoria “O ensaio estatístico da província cearense" (1860), um dos trabalhos mais importantes para a história do Ceará no século XIX, principalmente, no que diz respeito a dados estatísticos. O jornalista João Brígido também pode ser apontado como um dos nomes mais expressivos do jornalismo cearense durante toda a segunda metade do XIX. Apesar de ter nascido no Rio de Janeiro, muito cedo mudou-se para o Ceará, onde exerceu uma dinâmica carreira, publicando dezenas de artigos sobre a história desse estado. 
Era comum o uso de pseudônimos em virtude das perseguiçõos políticas. A legislação acerca das publicações impressas exigia que se destacasse somente o nome do impressor do jornal, o que, quase sempre, era feito na última linha da composição. Esse fato dificulta uma maior precisão na identificação dos autores dos artigos, o que, no entanto, não impossibilita uma investigação a esse respeito, pois atualmente sabe-se a quem pertenciam muitos dos pseudônimos utilizados pelos redatores.

O Cearense e A Constituição tinham uma grande divulgação em Fortaleza e também em outras cidades da província pois, como eram órgãos de partidos políticos, era quase uma obrigação para o filiado político ser assinante do jornal. A partir de algumas pistas em romance de época, como A Fome de Rodolfo Teófilo e A Normalista de Adolfo Caminha, como nos próprios anúncios nos jornais, pudemos constatar que a distribuição no interior da província chegava com um relativo atraso por meio de pacotes de correspondência e de informantes que faziam um elo entre o interior e a capital. É importante destacarmos que o espaço para a correspondência no jornal era fixo e nele publicavam-se cartas de leitores partidários de toda a província. No entanto, não é difícil que algumas dessas correspondências tenham sido escritas pelos próprios editores que, receosos de sofrerem atentados, escondiam-se sob a máscara do anonimato para fazer denúncias políticas.

Ao longo da segunda metade de século XIX, parece haver um aumento no número de leitores. É possível inferirmos tal fato a partir dos anúncios veiculados nos jornais, que passam a ter uma ou mais páginas disponíveis para esse fim. Um dos fatores responsáveis pelo aumento desses anúncios é também a diversificação da economia local. Inicialmente, os anúncios mais comuns diziam respeito à fuga de escravos, à venda de propriedades, e à oferta de emprego para aprendizes de tipógrafos, dentre outros assuntos.

Posteriormente, avolumam-se anúncios de lojas de roupa, livrarias, retratistas, perfumarias, farmácias, até mesmo de prestação de serviços de advogados, enfim, de diversos novos estabelecimentos comerciais que ofereciam seus produtos e serviços ao público da província. Isso nos leva a crer que tanto aumentou o número de leitores do jornal, como também estabeleciam-se novas necessidades a partir da própria publicidade jornalística.

Somente na década de 1860, segundo Geraldo Nobre (2006), foram registradas em Fortaleza quase 120 publicações entre jornais literários, noticiosos e científicos. Geraldo Nobre relata, inclusive, que houve a edição de uma revista jurídica quinzenal 
para o acompanhamento de processos em andamento em Fortaleza e na província em geral. O fato de, na cidade de Fortaleza, ser registrado esse grande número de publicações deve-se às próprias transformações que a levaram a emergir como capital e novo espaço urbano da província cearense. A presença de vários grupos políticos e intelectuais fazia com que a pequena cidade tivesse uma atividade cultural bastante intensa. Basta dizermos que estavam em pleno desenvolvimento várias sociedades artístico-culturais, como a Academia Francesa, a Fraternidade Cearense (loja Maçônica), Sociedade Recreio Instrutivo, Clube Literário de Fortaleza, além do Instituto Histórico e Geográfico do Ceará, da Padaria Espiritual , dentre outras. Para O Cearense, toda essa atividade artístico-cultural inaugurava um novo momento social:

\begin{abstract}
A humanidade caminha de progresso em progresso; a civilização, tomando-a pela mão, guia seus passos através das trevas [...] caminha agora como para uma nova redenção [...] encena-lhe o futuro desejado que a aguarda. Sinais precursores de um grande e próximo futuro de pontão por todo o urbe civilizado [...]. (O CEARENSE, 23/04/1852, p. 2-3).
\end{abstract}

O "grande e próximo futuro" parece apresentar-se como a própria construção de uma organização social respalda pela bandeira da civilização. A ênfase no refinamento dos hábitos, em novos códigos de conduta, era acompanhada por uma forte campanha que visava ao estabelecimento de instituições legais e normativas eficientes, à construção de cadeias e penitenciárias e à elaboração de um código penal rígido, que pudesse estabelecer novos parâmetros de conduta moral para a pequena cidade. $\mathrm{O}$ projeto de civilização que se construía pretendia ir muito além dos debates dos institutos e academias; ele visava, sobretudo, à modificação de comportamentos que operassem transformações no próprio dia a dia da cidade. Na composição de conceitos como nação, civilização e progresso, emerge um discurso poderoso sobre criminalidade e violência.

O papel de divulgação da violência pela imprensa se torna ainda mais relevante se levarmos em consideração a debilidade político-militar que tornava quase impossível um controle direto por parte do governo imperial sobre as diversas províncias, cabendo aos políticos locais essa função. Além de seu caráter moralizador, não se pode negar que notícias sobre crimes e fatos extraordinários alimentavam também a curiosidade dos leitores popularizando ainda mais a imprensa. Assuntos como assassinatos, acidentes, mortes extravagantes, bizarrices, etc., passaram a ser mais recorrentes nos periódicos do XIX e se tornam uma espécie de fenômeno consolidado com a organização da grande 
imprensa em fins do século XIX, são os chamados faits divers, termo cunhado no espaço da imprensa francesa para se definir uma categoria específica de notícia que se dedicaria a esses acontecimentos do dia a dia.

Para Roland Barthes, a principal característica do fait divers é ser "uma informação total, ou mais exatamente, imanente; ele contém em si todo seu saber: não é necessário conhecer nada do mundo para consumir um fait divers; ele não remete a nada mais, além dele mesmo." (BARTHES, 1966, p. 189 apud DION 2007, p. 125).

Todavia, no caso da imprensa cearense, pode-se perceber que a narrativa desses faits divers servia a um discurso civilizador, o que não retirava a dimensão chocante das narrativas dos acontecimentos. Os eventos antes tratados como particulares e isolados, ganham uma conotação pública, que pretendia atuar na transformação dos hábitos dos seus moradores. Dessa maneira, divulgar o crime, trazê-lo à cena pública, tornou-se uma importante ferramenta para coibi-los. Os assassinatos, ferimentos graves ou leves eram as uma das principais ocorrências criminais relatadas nos jornais do período, ao lado das matérias destinadas à política local.

Marcados por uma estrutura social rural - não esquecemos que o crescimento da cidade se alimentava de retirantes e outros grupos rurais - na qual predominavam códigos de honra pessoal e respeito ao senhor dono da terra, a violência se manifestava como um elemento constitutivo de integração social naquele cotidiano. Funcionava ainda como um mecanismo de ajustamento social, sobressaindo-se como padrão de comportamento associado à coragem pessoal, significando, ao mesmo tempo, uma demonstração de força e autoafirmação, de sobrevivência e autodefesa. No conjunto daquelas relações sociais, o senhor rural é visto não somente como o proprietário mas, como o orientador, prestador de serviços, o primeiro apoio procurado pelo camponês em caso de qualquer problema familiar. Representa também a imagem da justiça e da punição, efetivando um tipo de relação de dominação que se apresenta como sendo indiscutível e natural e que se solidifica em contatos familiares e de amizade. A este respeito nos fala César Barreira:

É interessante observar que o caráter "natural, familiar e eterno" dessa dominação envolve uma boa dose de mistério e desconhecimento. O mundo é difuso e misterioso e nele avultam o coronel e suas leis, o que facilita e torna também quase "natural" a reprodução da dominação. (BARREIRA, 1992, p. 18). 
Assim, entre aqueles grupos, há um código moral no qual a honra e a lealdade constituem os elementos principais. Tal código se funda numa legitimidade na qual a traição ou a quebra do compromisso moral se apresenta como comportamento inadmissível, uma identidade construída tendo como referência valores morais como honestidade, lealdade, gratidão e respeito à propriedade. Nesse contexto, colocava-se como o grande desafio para o processo de urbanização da capital cearense a construção de outros mecanismos de justiça e resolução de conflitos. Para isso, a imprensa atuou de maneira significativa como veremos a seguir.

\section{"A Publicidade do Crime"}

A contenção do crime era um dos aspectos mais debatidos entre os políticos e intelectuais cearenses. Em toda a província, eram comuns os "atentados contra a vida", fossem resultado de disputas político-partidárias, fossem manifestações de conflitos pessoais, a ponto de Tomaz Pompeo de Sousa Brasil afirmar em seu ensaio estatístico de 1860 que "o termo médio de atentados contra a vida é tão acrescido que só nos estados menos policiados da Europa dão uma proporção aproximada" (SOUSA BRASIL, 1860, p. 787).

A crítica a essas ocorrências é feita tendo como base o estabelecimento de um controle sobre a população. Moralizá-la seria o primeiro passo para civilizá-la pois, segundo O Cearense, enquanto isso não acontecesse, "não [haveria] pessoa por mais elevada, não [haveria] lugar por mais público que [estivesse] a abrigo do bacamarte ou do punhal do facínora" (26/07/1850, p. 2). Assim, para a efetivação da nação, da civilização e do progresso era preciso superar o "reinado do bacamarte".

Para editores dos jornais era inadmissível que os conflitos pessoais fossem resolvidos a bel prazer do envolvidos. As matérias sobre crimes tornavam-se ainda mais relevantes ao levarmos em consideração a debilidade político-militar que inviabilizava um controle direto por parte do governo imperial sobre as províncias, cabendo aos políticos locais essa função. Não por acaso, em 13 de agosto de 1876, A Constituição (13/08/1876) apresentava aos seus leitores uma matéria intitulada "A Publicidade do Crime”. Nela, o jornal procurava demonstrar a importância que a imprensa cearense assumia na divulgação das ocorrências criminais, tornando-as objeto de discussão pública, principalmente, a partir da década de 1850, quando o jornal supõe existir entre os cearenses "tanta facilidade de comunicação, tanta instrução, tanto melhoramento 
moral e material" (A CONSTITUIÇÃO, 13/08/1976), que seria imprescindível a existência de um mecanismo que se prestasse a discutir a questão criminal.

O jornal avalia que essa publicização funcionava como um aliado importante contra a impunidade, já que antes "nem a terça parte dos crimes chegavam ao conhecimento das autoridades superiores e do público" (A CONSTITUIÇÃO, 13/08/1976). Mas naquele momento, com a atuação da imprensa, o jornal assegurava que:

Dê-se o mais insignificante crime na província, se por ventura a polícia não o denuncia, imediatamente fá-lo a imprensa com toda a publicidade, por forma que se pode assegurar que nenhum delito fica por muito tempo desconhecido do público. (A CONSTITUIÇÃO, 13/08/1976).

Uma questão central apresentada no trecho é que ao estabelecer uma exposição sistemática sobre tais ocorrências, o jornal pretendia contribuir para que se desenvolvesse na população de Fortaleza um sentimento de rejeição sobre tais condutas. Para isso, a descrição dos acontecimentos deveria ser a mais detalhada possível, nos moldes dos faits divers de forma a causar no leitor espanto, indignação e repulsa, uma vez que "acumulação dos detalhes que dão credibilidade, os assuntos e as confidências, tanto dos autores dos crimes quanto das vítimas, [...] contribuem para a autenticidade da narrativa e a ilusão da proximidade" (DION, 2007, p. 126). Vejamos:

\begin{abstract}
O Infeliz Joaquim fora cruelmente surrado com espadeiradas e palmatoadas, arroches na cabeça, apertos de troquez e compasso nas partes genitais, e debaixo desses desumanos martírios conduzidos em pleno dia acompanhado daquelas autoridades (que pareciam ter perdido a cabeça) e seguido do demais povo pela rua que ficou sendo chamada a rua da amargura! [...] A infeliz Francisca de tal fora cruelmente castigada com palmatoadas e o delegado Manoel Joaquim Cavalcante enfurecendo-se a tal ponto, depois de com suas próprias mãos em presença do juiz de direito Carvalho, dar-lhes muitas palmatoadas arremessava-a no chão. Debaixo de todo este cortejo infernal foram conduzidos estas duas vítimas pela rua da amargura e postos na cadeia onde ainda hoje jazem debaixo de algemas. (A CONSTITUIÇÃO, 08/10/1865).
\end{abstract}

No trecho, apresenta-se aos leitores uma violência crua em um universo tenso, no qual as práticas violentas parecem emergir como elemento do dia a dia e nas relações sociais dos habitantes da cidade. A descrição sensacionalista ${ }^{4}$ do episódio tensiona a

\footnotetext{
${ }^{4}$ A utilização do conceito de sensacionalista aqui é empregada tendo como foco a constatação de que incidem sobre essas narrativas um tipo de prática jornalística de apelo ao emocional que encontra base na própria constituição da imprensa moderna. Assim, como afirma Ana Lucia S. Enne (2007), o sensacionalismo é um processo cultural que se estabelece em matrizes presentes desde os séculos XVIII e XIX, sendo os faits divers um canal para o que conhecemos contemporaneamente por sensacionalismo.
} 
cena pública e objetiva instaurar novos olhares sobre essas ocorrências. Ao mesmo tempo em que descreve a cena, o jornal expõe a perplexidade dos observadores diante dela ao acompanharem "o cortejo infernal” pelas ruas da cidade. A matéria acima faz parte da seção de correspondências do jornal. Sendo A Constituição um periódico ligado ao partido conservador, é importante notar que uma divulgação desse tipo servia a dois propósitos, atacar as práticas, mas também, ao governo local que, naquele momento, era representado o recém-empossado Barão Homem de Melo do partido Liberal. Assim, constata-se que, apesar do insistente discurso visando a uma moralização da população, a realidade apresentava-se bastante complexa, posto que, além do discurso civilizatório dos jornais, confluem nesse contexto interesse políticos e as dificuldades para instaurar novos hábitos entre as próprias autoridades.

A campanha pela reforma dos hábitos era um aspecto na mudança das atitudes da população diante dos mecanismos de controle e punição social. Todavia, o autoritarismo, a violência e o abuso de autoridade eram práticas comuns entre os agentes policiais, juízes, jurados, delegados e chefes de polícia, o que desvelava as contradições daquele sistema. Rotineiramente as autoridades locais estavam envolvidas em denúncias de proteção a criminosos ou conivência em crimes. Muitos artigos denunciavam abusos de autoridade, assassinatos, crimes políticos, e, principalmente, chamavam atenção para a necessidade de organização de um sistema policial eficiente. A própria atuação da polícia era um grave problema a ser superado, como nos demonstra essa passagem do jornal A Constituição:

\footnotetext{
É tristíssimo o estado em a que se acha reduzida a província! Não há dia em que não tenhamos de denunciar violência aos direitos, às pessoas, e à dignidade do cidadão; parece que vivemos em um país conquistado, onde não há outra lei si não a vontade do bárbaro vencedor. Tais são por toda a parte os excessos e destinos da polícia. (A CONSTITUIÇÃO, 27/10/1865, p. 2).
}

Reclamações dessa natureza podem ser explicadas pelo fato de que essas autoridades não estavam desligadas do cotidiano e das práticas que deveriam coibir; pelo contrário, estavam diretamente envolvidas nas experiências partilhadas naquele universo social. Muitos delegados, jurados, policiais eram nomeados sem que houvesse critérios claros de escolha; era comum que essas nomeações fossem feitas obedecendo a relações de amizade ou parentesco, o que resultava em muitos conflitos. O Cearense de 18 de janeiro de 1871 traz uma reclamação a respeito da proteção de criminosos por parte das autoridades: 
O Subdelegado de polícia do distrito de Várzea Grande, Raimundo Carneiro Portela, vai-se transviando de um modo deplorável e com detrimento da justiça pública, dispensando proteção a um indivíduo turbulento e criminoso. [...] pelo dito subdelegado acaba de ser nomeado inspetor de quarteirão [...] Joaquim Seriema Fontenelle, homem rixoso e de má reputação [...] sendo ele cunhado de um criminoso. (O CEARENSE, 18/01/1871, p. 1).

Ter sob controle essas ações não seria uma tarefa fácil pois, apesar do projeto de institucionalização de um aparato legal que procurava controlar a violência por formas racionalizadas de julgamento e punição baseadas no exercício legal da força em curso na província e em sua capital, havia um constante estado de tensão entre legalidade e legitimidade, elementos que se entrechocavam a cada encontro da polícia com a população. Essa tensão manifestada em Fortaleza intensificava-se não somente por ser a capital, mas principalmente por reunir uma série de fatores que a colocaram como centro nervoso de encontro de vários grupos sociais.

Os bairros pobres da cidade caracterizavam-se por uma alta rotatividade de moradores, uma vez que a maior parte deles recorriam à cidade em períodos de crise. $\mathrm{Na}$ maioria das vezes, marginalizados pela estrutura social e econômica, formavam grupos autônomos que desenvolviam seus próprios meios de sobrevivência. Em virtude disso, havia dificuldade em adaptarem-se aos códigos da cidade, fazendo com que fossem vistos pela elite fortalezense como pessoas desprovidas de qualquer senso moral e de autoridade. Como relatou o presidente Joaquim Villela de Castro Tavares, era inconcebível "que, na falta de autoridades constituídas" os indivíduos tivessem "plena liberdade de seguir o ímpeto das paixões mais violentas, holocaustrando à vingança as vítimas de seus entranháveis ódios” (TAVARES, 1853, p. 5).

Não esquecemos, como foi dito no começo, que a capital era um grande mosaico de vozes no XIX, uma incrível flutuação de pessoas que corriam para a cidade em períodos de calamidades como epidemias e secas. Por outro lado, constata-se a prosperidade ligada a comerciantes, donos de terra, intelectuais, famílias tradicionais que faziam de Fortaleza um espaço em constante tensão social.

Nesse cenário de fraturas a imprensa construiu para si um papel de "pugnar para que a segurança individual e de propriedade fosse por toda parte mantida pelos meios que a lei consagra" (O CEARENSE, 05/06/1857, p. 1), estando sempre vigilante e atenta à defesa da liberdade individual, que segundo O Cearense, era um "nobre empenho" que deveria ser colocado acima de todas as "sugestões políticas", e do espírito partidário (O CEARENSE, 05/06/1857, p. 1). Somente se a "população 
estivesse habituada a ver impressa a lei”, a estatística criminal deixaria de tomar "proporções espantosas nos representando fora do país como feras indomáveis" (O CEARENSE, 14/07/1874).

A ordem vinha acompanhada pela necessidade de civilização dos hábitos. Para esses grupos, um novo homem também era esperado para esse momento: um homem que pudesse controlar seu próprio despotismo e que se submetesse a uma sociedade de regras, a uma sociedade de leis, aspectos destacados pelo jornal $\mathbf{O}$ Cearense ao saudar o ano de 1850: "Ano de 1850, sejas bem-vindo! Ah possas tu por teus benefícios fazer esquecer os males do teu predecessor! Possas tu ver firmada para sempre a liberdade dos povos e salva a causa da civilização e da humanidade" (O CEARENSE, O ano de 1850, 05 /01/1850, p. 1).

Segundo Norbert Elias, um dos elementos mais importantes nesse processo reside no fato de que a marcha civilizatória estabelece novos medos, novos padrões de proibição e punição. O sentimento de vergonha e repulsa diante de determinadas ações instaura um controle internalizado. Nesse espaço que se construía, a violência direta, as disputas pessoais e individualizadas tornam-se aparatos inaceitáveis. A modelação do homem civilizado está intimamente ligada à rede de interdependências, à qual ele se associa. Como nos diz o autor:

Toda essa reorganização dos relacionamentos humanos se faz acompanhar de correspondentes mudanças nas maneiras, na estrutura da personalidade do homem, cujo resultado provisório é nossa forma de conduta e de sentimentos civilizados. (ELIAS, 1997, p. 195).

Esse homem é influenciado constantemente pelas pressões, pela variedade e pela complexidade das atividades com as quais tem de se preocupar pois, "tornando-se o tecido social mais intrincado, o aparato sociogênico de autocontrole individual, torna-se também mais diferenciado, complexo e estável." (ELIAS, 1997, p. 195). Como nos alerta Elias, esse autocontrole é introduzido de forma cotidiana desde a infância e se constitui a partir de um cerco tão bem estruturado que dificilmente o indivíduo poderá se libertar ou mesmo transgredi-lo sem se sentir culpado por fazê-lo.

Nesses termos, o aparato de autocontrole mental vai sendo impelido a uma íntima relação com a monopolização da força, exercida principalmente pelo Estado pelos mecanismos coercitivos como a polícia e o exército. Na verdade, o controle sobre a violência constitui um dos elementos mais importantes dentro da organização da sociedade civilizada. A força agora não poderá ser exercida pelo indivíduo comum em 
seu dia a dia, ela será oficialmente controlada por um grupo especializado para isso. Progressivamente, a sociedade elabora novas sensibilidades sobre as ações violentas, construindo uma série de recursos materiais e simbólicos que lhe revestirão de novos significados dentro do mundo civilizado.

Portanto, o que estava em jogo nesse momento era a construção de mecanismos monopolistas tanto institucionais, como simbólicos. Além de um corpo policial cada vez mais presente nas ruas da cidade, da construção de instituições corretivas e da atuação de tribunais em disputas cotidianas, era necessário que o mínimo de consenso e adesão por parte da população fosse alcançado.

Os discursos apresentados pelos jornais manifestavam-se sob diferentes níveis morais a cada novo acontecimento deflagrado na cidade. Fosse discutindo o problema da autoridade, fosse criticando os costumes da população, a imprensa tornava-se protagonista na defesa do processo de centralização da força na capital e na província. Se, por um lado, a administração provincial agia na organização do contingente policial e na construção de cadeias e penitenciárias, por outro, a imprensa tinha a importante tarefa de construir simbolicamente mecanismos de normatização por meio do insistente discurso sobre violência e justiça.

Tratava-se de uma intensa luta no sentido de estabelecer o convencimento da população e a adesão desta à "justiça pública" como "garantidora dos sagrados direitos do cidadão" (A CONSTITUIÇÃO, 21/07/1867, p. 1). Apesar dos jornais atribuírem aos grupos pobres da cidade a responsabilidade pela maioria dos crimes acontecidos em Fortaleza, observa-se que os grupos dominantes não estão a salvo das críticas da imprensa. Isso reforça o fato de que mesmo os defensores da lei e da ordem tinham dificuldades de adaptação aos próprios códigos que defendiam. A aplicação da lei muitas vezes poderia detonar conflitos que eram imprevisíveis e que geravam uma violência maior do que a que queria reprimir, fazendo com que o criminoso passasse de infrator à vítima da justiça que se tornava, segundo O Cearense (18/03/1857), "uma verdadeira antítese de sua significação". Assim, o jornal indagava com indignação:

\footnotetext{
De que serve então essa Constituição e código que manda que ninguém será preso sem culpa formada, salvo nos casos marcados na lei? Onde está a garantia da liberdade e segurança individual proclamada tão solenemente na Constituição, se qualquer agente da polícia pode prender e conservar na prisão um cidadão porque se diz que é criminoso sem que se prove seu crime ou se instaure processo? (O CEARENSE, 18/03/1857).
} 
Para que a centralização se tornasse possível, era necessário a introdução de elementos que pudessem proporcionar um equilíbrio de poderes que sustentassem e justificassem esse monopólio. As relações monopolistas deveriam estruturar-se sob uma dependência que agiria não somente a partir de relações de opressão física, mas também por meio de mecanismos simbólicos que pudessem atuar, modificando necessidades e sensibilidades sociais, cobrando de cada indivíduo envolvido uma atuação concordante com as necessidades desse monopólio. Isso somente seria possível por meio de uma rede de interdependência, pois, como afirma Norbert Elias,

\begin{abstract}
quanto mais pessoas são tornadas dependentes pelo mecanismo monopolista, maior se torna o poder do dependente, não apenas individual mas também coletivamente, em relação a um ou mais monopólios. Isso acontece não só por causa do pequeno número que galgam a posição monopolista, mas devido à sua própria dependência de cada vez mais dependentes, para preservarem e explorarem o potencial de poder que monopolizam. (ELIAS, 1997, p. 100).
\end{abstract}

Dessa maneira, o estabelecimento do monopólio da força física pretendia fazer com que os mecanismos de lutas fossem refinados e sublimados. Os conflitos que antes aconteciam "livremente" como ações individuais compreendidas dentro de códigos sociais baseados no pragmatismo do dia a dia, passam a ser limitados pela ação burocratizada de instituições sociais construídas e pensadas para esse fim. Progressivamente, a divisão das funções humanas e a subordinação dessas a uma série de instâncias suprimem a monopolização privada dos recursos.

No decorrer do processo de organização da justiça na capital, a atuação policial vai assumindo um papel cada vez maior como asseguradora da ordem (BARBOSA, 1997, p. 38), tanto que, cada vez mais, são dispensadas maiores verbas para armar e dar condições estruturais à atuação da polícia. O número das despesas com o corpo policial praticamente triplicou em dez anos ${ }^{5}$. Esse fator é característico da necessidade de maior centralização da força pelo Estado. Em termos burocráticos, ainda não se pode afirmar que o Estado tivesse em suas mãos o controle da situação.

Em termos práticos, não havia uma definição clara sobre o papel que deveria desempenhar a polícia dentro da comunidade; nas matérias dos jornais, fica claro que nem os próprios policiais compreendiam suas funções. Na maioria dos casos, eram extremamente autoritários e violentos, além de se utilizarem de seu cargo para

\footnotetext{
5 Os números são os seguintes: 1852; 22:289\$354, 1853; 27: 318\$238, 1854; 30:003\$834, 1855; $32: 817 \$ 490, \quad 1856 ; \quad 39: 817 \$ 145, \quad 1857 ; \quad 45: 220 \$ 374, \quad 1858 ; \quad 54: 875 \$ 371, \quad 1859 ; \quad 57: 355 \$ 461$, 1860;59:740\$426, 1861; 59:517\$838 TOTAL; 428:463\$531 (JUNIOR, 1862).
} 
intimidarem outros membros da comunidade. Vejamos um exemplo extraído do jornal A Constituição (27/10/1865), no qual é relatada a atuação policial em uma diligência em busca de um suspeito:

\begin{abstract}
A escolta o seguiu no encalço e ao entrar no mato tropeçando e caindo o fugitivo, os perseguidores começaram a bater-lhe desapiedamente a cacete, deixando-o sem sentido e todo lavado de sangue, que burbulhava-lhe das grandes brechas que lhe abriram na cabeça e em outras partes do corpo. A mãe da vítima, e uma sua irmãzinha correram ao lugar do sacrifício em socorro da vítima e este ato de nobre dedicação foi correspondido por novos espancamentos sobre aquelas inofensivas criaturas. (A CONSTITUIÇÃO, 27/10/1865).
\end{abstract}

Nos bairros e nas ruas de Fortaleza, a violência policial era uma constante, o que pode ser observado no papel desempenhado pelos inspetores de quarteirão. Geralmente, o cargo de inspetor de quarteirão deveria ser exercido por um membro do bairro que pertencesse à reserva da guarda nacional e que conhecesse bem todas as casas e os moradores do quarteirão pelo qual seria responsável. Entretanto, vários eram os problemas em torno da nomeação desses homens, pois há relatos nos jornais de que muitos deles eram conhecidos criminosos e tornavam-se "célebres na prática de prisões ilegais ou violentas" (O CEARENSE, 21/05/1871). Em outra ocasião, era assim que o jornal A Constituição, em agosto de 1865, descrevia o inspetor de quarteirão de Arronches, um dos subúrbios de Fortaleza:

É um indivíduo sem moralidade alguma [...] não há muito saiu da cadeia desta cidade, onde cumpriu pena por crime de roubo e afronta continuamente a moralidade pública tendo consigo uma mulher casada que tomou do marido (A CONSTITUIÇÃO, 20/08/1865).

Também as nomeações de autoridades de altas patentes eram feitas a partir de indicações políticas que sustentavam uma poderosa rede de troca de favores eleitorais. Mesmo aqueles que compunham o corpo de polícia ou ocupavam cargos mais inferiores, quando não eram indicados por amigos partidários, eram convocados compulsoriamente por meio de recrutamento, o que causava verdadeiros transtornos à população. Apesar de existirem critérios para a prática do recrutamento, muitas vezes esse mecanismo servia como forma de intimidação pessoal ou de vingança política. Vejamos como o jornal O Cearense, em 1850, relatava os recrutamentos feitos na província: 
Já fizemos ver aos nossos leitores em números passados o como se faz o recrutamento entre nós, à bala, arrombando-se portas, varejando-se casas à noite, amarrando-se a Constituição e vestuariando-se raparigas para reconhecer-se os sexos, arrancando-se doentes do leito para estuporarem e morrem daí a poucas horas. (O CEARENSE, 03/06/1850).

Assim, a entrada na carreira militar era motivo de temor para boa parte da população. O contato com a autoridade policial desencadeava uma adaptação traumática aos códigos urbanos em elaboração, pois chocava-se de frente com relações sociais organizadas a partir de outros padrões de aceitação e legitimidade. A presença policial apresentava-se como um elemento estranho, um intruso assustador de certa forma, incompreensível, ou então, como problema. Reclamava a esse respeito o presidente da província Joaquim Marcos de Almeida Rego:

Da minha parte tenho empregado todos os meios que pode dispor a presidência para captura e punição dos criminosos, mas as indiferenças e o pouco zelo que algumas autoridades mostram pelo serviço público encarando crimes atrozes como fatos ordinários e de pouco monta, impede a eficácia das medidas empregadas na apreensão dos crimes. (RELATÓRIO, 1851, p. 1). ${ }^{6}$

A ênfase dada à organização de polícias especializadas para as cidades é uma tendência nos principais centros urbanos em todo o século XIX. Desse modo, a especificidade do desenvolvimento urbano das cidades modernas deflagrou novas formas de estruturação para esse setor. Como afirma Francisco de Souza (1998, p. 265293), “a criação da polícia metropolitana constituiu um marco importante tanto no combate ao crime quanto na definição dos princípios gerais que permitiram a emergência de um novo conceito de ordem urbana e do padrão de sociabilidade admitida" (SOUZA 1998, p. 265-293).

A certeza da punição e da vigilância contínua feita por grupos especializados traziam à tona um novo modelo de controle cuja principal característica era estimular no indivíduo o desenvolvimento de mecanismos de autocontrole que pudessem criar novos hábitos sociais e morais. Segundo Francisco de Souza,

\footnotetext{
a vigilância promovida pelos aparelhos policiais do estado teria a principal função de controlar o crime como forma de reprimir as 'classes perigosas', o protesto social ou as ameaças políticas. O próprio processo de urbanização teria imposto uma pressão maior e mais generalizada no sentido do autocontrole individual e de formas não violentas de resolução de conflitos. (SOUZA, 1998, p. 265-293).
}

\footnotetext{
${ }^{6}$ Relatório com que o Exmo. Sr. Presidente de Província Joaquim Marcos de Almeida Rego, abriu a sessão da Assembleia Legislativa provincial, no dia 1 de outubro de 1851 p. 04.
} 
A existência de uma polícia especializada na vigilância urbana representava o olhar de uma nova legalidade sobre o universo dos grupos sociais que passaram a habitar as cidades. Era uma maneira de homogeneizar formas de resolução de conflitos, punição e lei, já que cada um dos grupos que compunham a cidade detinha formas próprias de relacionamento e comportamento.

A necessidade de organização de um sistema policial eficaz aparece como um ponto chave nos discursos dos políticos e intelectuais cearenses, como nos demonstra esse trecho do jornal A Constituição, de julho de 1867, quando o vice-presidente da província, Sebastião Gonçalves da Silva, afirmava que:

Esta capital é importante por sua população já necessitar de uma polícia inteligente; não é seguramente um serviço feito por soldado bisonho que pode responder por interesse de tal ordem. (A CONSTITUIÇÃO, 1967).

Ainda segundo o vice-presidente, o policial ideal para as cidades, principalmente para a capital, é aquele "guarda que conheça seus habitantes, seus hábitos, que para perseguir o criminoso tem a necessária aptidão". Todavia, ao contrário de funcionar como mecanismo de prevenção do crime a atuação policial, estava constantemente envolvido em conflitos deflagrados pelas ruas da cidade, a ponto de $\mathbf{O}$ Cearense (24/03/1871, p. 1) perguntar:

Que papel representa a nossa polícia? Se aqui mostra-se fraca, indiferente a tudo quanto se passa em torno dela, ali converte-se em instrumento de paixões desordenadas, cruzando os braços, senão tomando parte imediata nas questões que comprometem a tranquilidade pública. (O CEARENSE, 24/03/1871, p. 1).

Para os intelectuais presentes na capital cearense, Fortaleza deveria ser um modelo de civilização e ordem, a capital de uma pretensa Belle Époque cearense, com ruas largas, prédios imponentes, pessoas com bons costumes, festas e roupas sofisticadas, compradas em lojas que se achavam "sempre em dia com a última moda do mundo civilizado" (A CONSTITUIÇÃO, 16/03/1867).

Aparentemente, a Fortaleza que se constrói na segunda metade do século XIX é uma cidade que representava a própria imagem do desenvolvimento do progresso e da civilização, como dizia o jornal A Constituição já em 1867: "está tudo mudado; que progresso espantoso, aí se nota! É uma grande e bela cidade [...] toda empedrada do melhor modo e praças arborizadas [...] é o progresso material que se ostenta aqui de modo incrível" (A CONSTITUIÇÃO, 28/03/1867). 
$\mathrm{Na}$ verdade, a Fortaleza urbanizada e em franco progresso apresentada pela imprensa cearense deve ser vista como espaço em construção e movimento que comporta tanto práticas tradicionais, assim, como uma estrutura urbana eficaz apenas para parte de sua população. As constantes reclamações da população acerca dos conflitos policiais nos relevam as diferenças de uma cidade idealizada e de uma cidade realizada na qual ainda predominavam relações sociais marcadas por uma estrutura tradicional rural, por ruas repletas de casebres, pela falta de emprego para a maioria dos habitantes. O que se apresenta em Fortaleza é uma sobreposição de signos e costumes. Uma nova rede de relacionamentos humanos, de necessidades e sensibilidades se construía se sobrepondo a antigas formas de comportamento. O aumento de crimes e de conflitos é um reflexo desse choque, o que de certa forma explica as deficiências policiais e as dificuldades que a própria população da capital encontra para se adaptar aos códigos legais e às posturas urbanas.

Se, por um lado, a atuação policial deveria manifestar-se como um símbolo de civilização, na medida em que representava o controle da força física nas mãos do Estado, a organização de grupos especializados para exercerem uma vigilância cotidiana sobre os habitantes da cidade, por outro, a forma como ela se organiza em Fortaleza é a própria representação de uma civilização possível que ia se moldando na capital da província. Desde o começo, a cidade emerge como um lugar repartido, cheio de fissuras e contradições.

Apesar de representar uma nova legalidade, a atuação da polícia era baseada em ações individualizadas e algumas vezes arbitrárias, pois geralmente o policial, ou o delegado, antes de submeter o acusado aos procedimentos legais e institucionais, impunha-lhe sua própria lei. Por isso, O Cearense chama atenção do presidente Homem de Mello para "o nepotismo de certas autoridades, que supondo gozarem de imunidade, vão castigando com pancadas aqueles que se atrevem a queixar-se ao governo contra suas arbitrariedades" (O CEARENSE, 16/09/1865).

Até o final do século XIX, vemos uma cidade em constante conflito sobre a efetivação dessas práticas, especialmente, nos encontros entre os prováveis criminosos e aqueles responsáveis pela vigilância, julgamento e punição. Ocasionalmente, as autoridades policiais assumiam o lugar que antes era do capanga político, do pistoleiro ou do agregado dos proprietários de terra: 
O Dr. Juiz de direito, o delegado do termo e o subdelegado [...] submeteram a torturas um pobre homem envolvendo-lhe a cabeça em um arrocho de cordas com tal força que os bugalhos saltaram-lhe das órbitas. Essa tortura era empregada para o descobrimento de um furto, mas tendo ela sido insuficiente, novas torturas foram aplicadas, palmatoadas e açoites [...] tratase de um crime horrendo! Três autoridades sem nem uma forma da lei constituindo-se em tribunal impõem a cidadãos desvalidos penas aviltantes que estiveram em voga no antigo regime, mas que por honra da humanidade foram abolidas pela constituição do Estado (A CONTITUIÇÃO, 26/10/1865).

O constrangimento e a tortura que se apresentam como práticas comuns nas investidas cotidianas da polícia sobre a população de Fortaleza refletem a problemática passagem de um sistema tradicional, baseado em relações comunitárias e pessoais, para a introdução de um tipo de autoridade institucional e estatal o que, segundo Francisco de Souza (1998, p. 273), não permitiu um refinamento imediato das práticas policiais. Não havia uma preparação efetiva daqueles que iam exercer a função de policiamento da cidade. Como vimos, a escolha dos homens que exerceriam os cargos na polícia quase sempre se dava com uma indicação política em troca de favores, o que gerava os gravíssimos problemas de abuso de autoridade e violência policial.

Era violenta e irregular a atuação policial exercia um poder de coerção e vigilância bastante forte no cotidiano da cidade, tanto que, na década de 1850 , com o estabelecimento do toque de recolher, "a polícia não permitia que, na cidade, depois das 9 horas da noite, continuasse o trânsito público" (CRUZ ABREU, apud SOUZA, 1934, p.127-130). No quartel de polícia, as notas compassadas da corneta, que podiam ser escutadas até mesmo nos locais mais afastados da pequena cidade, "estugavam o passo dos retardatários em busca de suas habitações. Ouvia-se, então, na praça Carolina, o ruído das portas das tavernas, que se fechavam apressadamente e o burburinho alvoroçado da gente que se retirava" (CRUZ ABREU, apud SOUZA, 1934, p. 127-130).

\section{Considerações finais}

A pretensão maior dos discursos construídos na imprensa cearense era estabelecer a "causa da civilização". Assim, um grande empecilho deveria ser enfrentado: a violência como prática socialmente aceita na cidade, principalmente, aquela exercida fora dos padrões de legalidade preconizados para o espaço urbano. Desse modo, deveriam estruturarem-se mecanismos de controle e punição para as ações violentas praticadas entre os diversos grupos da cidade, fazendo com que, 
progressivamente, as antigas formas de resolução de conflitos deixassem de ser reconhecidas como recursos legítimos para cair na ilegalidade do crime.

A introdução de novos padrões de julgamento e punição em Fortaleza encontrou sérias dificuldades de efetivação, pois os próprios agentes que trabalhavam como policiais e inspetores de quarteirão não tinham clareza sobre o desempenho de suas funções ou os limites de sua atuação. Em virtude disso, os jornais apresentavam frequentemente denúncias de abuso de autoridade e de violência policial.

Mais do que o controle físico, os jornais defendiam mecanismos de autocontrole e a normatização burocratizada que deveria agir diariamente sobre as relações sociais definindo hábitos e condutas. Dessa forma, pretendiam realizar a distinção entre relações sociais fora da lei, nas quais os indivíduos definiam seus próprios mecanismos de luta e justiça, e relações sociais rigidamente controladas e hierarquizadas, nas quais cabia ao Estado o controle da força e a aplicação da justiça.

Nesse cenário, a atuação da imprensa investe na divulgação de discursos moralizadores sobre a violência apresentados em um duplo objetivo: em primeiro lugar criar uma rejeição pública cada vez maior sobre a violência na capital. Em segundo, construir referenciais legais e burocratizados no tratamento dessas posturas.

O discurso dos intelectuais e políticos da capital cearense no século XIX baseouse em três elementos fundamentais: o primeiro deles era construir um ideal urbano, simbólico e material para Fortaleza. Como podemos perceber, a cidade de Fortaleza ainda estava em um lento processo de estruturação urbana e, em virtude disso, podemos sentir, durante todo esse período, uma batalha incessante que alguns grupos da cidade assumem para transformá-la em centro de referência para toda a província. Um segundo elemento, que está profundamente ligado ao primeiro, era que transformá-la em um centro urbano implicava em civilizá-la, difundir entre os seus habitantes novos hábitos e novas condutas, fazendo com que surgisse entre a população uma rede de relações sociais mais burocratizadas e interdependentes. Ficaria estabelecido, dessa forma, um entrelaçamento social no qual cada vez mais os habitantes da cidade se sentissem dependentes entre si. E, finalmente, o terceiro elemento que, inclusive, era fundamental para a efetivação dos dois primeiros, consiste exatamente na construção de mecanismos de controle para a violência. Somente a organização de um aparato centralizador da força física e o estabelecimento de um rigoroso código de condutas morais, baseados na observação de uma nova noção de autoridade e justiça, poderiam conceder à capital ares de urbanidade, civilização e moralidade. 
O ritmo dessas transformações apresentou-se ora lentamente, por meio de mecanismos sutis de convencimento e introjeção de valores, nos quais a participação da imprensa foi fundamental; ora violenta e abruptamente, por meio da coerção policial, imposição de trabalhos corretivos e normatização de condutas pelos códigos de postura. Nesses momentos de continuidade e descontinuidade, surgiam outros significados sobre as condutas da cidade. Outros signos nasciam sob a lógica civilizatória.

Dessa forma, a configuração social de Fortaleza, em toda a segunda metade do século XIX, é marcada por uma conflituosa convivência entre hábitos classificados como "incivilizados" e um discurso insistente que buscava estabelecer um controle sobre esses hábitos. Se, por um lado, havia em Fortaleza grupos que se apresentavam como representantes dos padrões urbanos civilizados, por outro, havia também uma população bastante diversificada, pessoas que em sua maioria tinham fortes laços com o meio rural e que, de certa forma, estavam bastante distantes da civilização defendida para a capital cearense. É necessário que se perceba que, no contato entre os diversos habitantes da capital cearense, estabeleceu-se um dramático conjunto de posições estratégicas com a influência ativa dos que pretendiam estabelecer uma nova realidade social na cidade, como também daqueles que estavam sendo submetidos a essas, desencadeando-se, assim, uma permuta de concessões e resistências. 


\section{REFERÊNCIAS}

Fontes primárias

BIBLIOTECA NACIONAL (Brasil). Hemeroteca Digital Brasileira. A Constituição, 20/08/1865.

BIBLIOTECA NACIONAL (Brasil). Hemeroteca Digital Brasileira. A Constituição, 08/10/1865.

BIBLIOTECA NACIONAL (Brasil). Hemeroteca Digital Brasileira. A Constituição, 26/10/1865.

BIBLIOTECA NACIONAL (Brasil). Hemeroteca Digital Brasileira. A Constituição, 27/10/1865.

BIBLIOTECA NACIONAL (Brasil). Hemeroteca Digital Brasileira. A Constituição, 16/03/1867.

BIBLIOTECA NACIONAL (Brasil). Hemeroteca Digital Brasileira. A Constituição, 28/03/1867.

BIBLIOTECA NACIONAL (Brasil). Hemeroteca Digital Brasileira. A Constituição, 06/07/1867.

BIBLIOTECA NACIONAL (Brasil). Hemeroteca Digital Brasileira. Constituição, 21/07/1871.

BIBLIOTECA NACIONAL (Brasil). Hemeroteca Digital Brasileira. A Constituição, 13/08/1876.

BIBLIOTECA NACIONAL (Brasil). Hemeroteca Digital Brasileira. A Constituição, 26/04/1970.

BIBLIOTECA NACIONAL (Brasil). Hemeroteca Digital Brasileira. O Cearense. 05 /01/1850.

BIBLIOTECA NACIONAL (Brasil). Hemeroteca Digital Brasileira. O Cearense, 03/06/1850.

BIBLIOTECA NACIONAL (Brasil). Hemeroteca Digital Brasileira. O Cearense, 26/07/1850.

BIBLIOTECA NACIONAL (Brasil). Hemeroteca Digital Brasileira. A Queda de Rosas. O Cearense, 23/04/1852. p. 2-3.

BIBLIOTECA NACIONAL (Brasil). Hemeroteca Digital Brasileira. O Cearense, 18/03/1857. 
BIBLIOTECA NACIONAL (Brasil). Hemeroteca Digital Brasileira. O Cearense, 05/06/1857.

BIBLIOTECA NACIONAL (Brasil). Hemeroteca Digital Brasileira. O Cearense, 16/09/1865.

BIBLIOTECA NACIONAL (Brasil). Hemeroteca Digital Brasileira. O Cearense, 18/01/1871.

BIBLIOTECA NACIONAL (Brasil). Hemeroteca Digital Brasileira. O Cearense, 24/03/1871.

BIBLIOTECA NACIONAL (Brasil). Hemeroteca Digital Brasileira. O Cearense, 21/05/1871.

BIBLIOTECA NACIONAL (Brasil). Hemeroteca Digital Brasileira. O Cearense, 14/07/1874.

BIBLIOTECA NACIONAL (Brasil). Hemeroteca Digital Brasileira. O Cearense, 19/08/1953.

JUNIOR, Cunha Figueiredo. Relatório do Presidente da Província. 1 de outubro de 1862.

RELATÓRIO de presidente de província. 1/10/1851.p. 1.

TAVARES, Castro. Relatório de presidente de província. 1853. p. 5.

\section{Fontes secundárias}

BARBOSA, Francisco Carlos Jacinto. A Força do Hábito: Condutas Transgressoras na Fortaleza Remodelada 1900-1930. 1997. Dissertação (Mestrado em Sociologia) Universidade Federal do Ceará, Programa de Pós-graduação em Sociologia, Fortaleza, 1997.

BARTHES, Roland. Essais Critiques. Paris: Éditions De Seuil, 1964.

BARREIRA, César. Trilhas e atalhos do poder - conflitos sociais no sertão. Rio de Janeiro: Rio fundo Editora, 1992.

BRESCIANI, Maria Stella Martins. Lógica e Dissonância Sociedade de Trabalho: Lei, Ciência, Disciplina e Resistência Operária. Revista Brasileira de História, São Paulo, v. 6, n. 11, p. 7-44, set. 1985/fev., 1986.

BRETAS, Marcos Luiz. Ordem na cidade - o exercício cotidiano da autoridade policial no Rio de Janeiro 1907-1930. Rio de Janeiro: Rocco, 1997.

BRETAS, Marcos Luiz. A guerra das ruas - povo e polícia na cidade do Rio de Janeiro. Rio de Janeiro: Ministério da Justiça/Arquivo Nacional, 1997. 
BRETAS, Marcos Luiz. O crime na historiografia brasileira - uma revisão na pesquisa recente. BIB, Rio de Janeiro, n. 32, p. 46-61, 1991.

BRETAS, Marcos Luiz. A polícia carioca no Império. Estudos Históricos, Rio de Janeiro, v. 12, n. 22, p. 219- 234, 1998.

BOURDIEU, Pierre. O poder simbólico. Lisboa: DIFEL, 1989.

CARVAlHO, José Murilo de. A formação das almas: o imaginário da república no Brasil. São Paulo: Companhia das Letras. 1998.

CARVAlHO, José Murilo de. A construção da ordem. $2^{\text {a }}$ ed. Revisada. Rio de Janeiro: Editora UFRJ/RELUME-DUMARA, 1996.

CARVALHO, José Murilo de. Teatro de sombras. $2^{\text {a }}$ ed. Revisada. Rio de Janeiro: Editora UFRJ/RELUME-DUMARA, 1996.

CARVALHO, José Murilo de. Os bestializados: o Rio de Janeiro e a República que não foi. São Paulo: Companhia das Letras, 1987.

CERTEAU, Michael de. A Invenção do Cotidiano - Artes de fazer. $3^{\text {a }}$. ed. Petrópolis: Editora Vozes, 1998.

CHARTIER, Roger. A História Cultural: entre práticas e representações. Coleção Memória e Sociedade. Lisboa: Difel, 1990.

CHARTIER, Roger. Práticas de Leitura. Brasília: Estação Liberdade, 1996.

CHARTIER, Roger. A Ordem dos Livros, leitores, autores e bibliotecas nas Europa entre os séculos XIV e XVIII. Brasília: Editora UNB, 1994.

DARMON, Pierre. Médicos e assassinos na Belle Époque. Rio de Janeiro: Paz e Terra, 1991.

DION, Silvie. O "fait divers" como gênero narrativo. Revista34 P\&B. 123 10/10/2007.

ELIAS, Norbert. O processo civilizador: uma história dos costumes. Trad. Rui Jungmann. vol. I. Rio de Janeiro: Zahar, 1997.

ELIAS, Norbert. O processo civilizador: formação do Estado e civilização. Trad. Rui Jungmann. vol. II. Rio de Janeiro: Zahar, 1996.

FOUCAULT, Michael. Microfísica do poder. Trad. Roberto Machado. $6^{\mathrm{a}}$ ed. Rio de Janeiro: Graal, 1986.

FOUCAULT, Michael. Vigiar e punir: história da violência nas prisões. Trad. Lígia M. Pondé Vassalo. $5^{\text {a }}$ ed. Petrópolis: Vozes, 1987. 
FRANCO, Maria Silvia de Carvalho. Homens livres na ordem escravocrata. São Paulo: Instituto de Estudos Brasileiros/ Universidade de São Paulo, 1969.

HANNAH, Arendt. Sobre a violência. Rio de Janeiro: Relume - Dumará, 1994.

HOBSBAWM, Eric. RANGER, Terence. A invenção das tradições. $2^{\mathrm{a}}$. ed. São Paulo: Paz e Terra, 1997.

IGNATIEFF, Michael. Instituições totais e classes trabalhadoras: um balanço crítico. Revista Brasileira de História, São Paulo, n. 14, p. 185-193, 1987.

LEMENHE, Maria Auxiliadora. As razões de uma cidade. Fortaleza: Ed. Stilus Comunicação, 1991.

NOBRE, Geraldo da Silva. Introdução à história do jornalismo cearense. Ed. FacSimilar. Fortaleza, Nudoc. 2006.

OUTRO Aramac, (um dos pseudônimos utilizados por João Brígido) Documentário "Fortaleza da 1845" - Almanaque do Ceará, para o ano de 1845, se voltar organizado de memória, e sob documentos. Revista do Instituto Histórico e Geográfico do Ceará, t. 72, p. 230-256, 1958.

PERROT, Michelle. Os excluídos da história: operários, mulheres, prisioneiros. Trad. Denise Bottmann. Rio de Janeiro: Paz e Terra, 1988.

RAGO, Luzia Margareth. Do cabaré ao lar. A utopia da cidade disciplinar - Brasil 1890-1930. 2 ed. Rio de Janeiro: Paz e Terra, 1985.

ROSSI, Aldo. A arquitetura da cidade. São Paulo: Martins Fontes, 1995.

SANTOS, Afonso Carlos Marques dos. Memória Cidadã: História e Patrimônio Cultural. Anais do Museu Histórico Nacional, Rio de Janeiro, v. 29, p. 37-55, 1997.

SANTOS, Afonso Carlos Marques dos. A cidade do Rio de Janeiro: de laboratório da civilização a cidade símbolo da nacionalidade. Mímeo.

SOUSA, Thomaz Pompeo Brasil de. Ensaio estatístico da Província do Ceará. Ed. fac-similar publicada em 1863. Coleção Biblioteca Básica Cearense. Fortaleza: Fundação Waldemar Alcântara, tomos I e II, 1997.

SOUZA, Luiz Antônio Francisco. Autoridade, violência, e reforma policial. A Polícia preventiva através da historiografia de língua inglesa. Estudos Históricos, Rio de janeiro, Fundação Getúlio Vargas, v. 12, n. 22, p. 265-293, 1998.

TEÓFILO, Rodolfo. A fome. Rio de Janeiro: Livraria José Olympio Editora, 1979.

TEÓFILO, Rodolfo. Violação. Rio de Janeiro: Livraria José Olympio Editora, 1979.

TEÓFILO, Rodolfo. Varíola e vacinação no Ceará. Ed. Fac-similar da edição publicada em 1904. Fortaleza: Fundação Waldemar Alcântara, 1997. 
ZENHA, Celeste. As práticas da Justiça no cotidiano da pobreza. Revista Brasileira de História, São Paulo, n. 10, p. 185-193, 1985. 